\title{
Uma abordagem lúdica no ensino de Pensamento Computacional para crianças
}

\author{
Renata Silva - Instituto Federal de Educação Ciência e Tecnologia do Sertão \\ Pernambucano Campus Petrolina - renata.silva@aluno.ifsertao.edu.br - \\ https://orcid.org/0000-0003-1097-9243
}

Fábio Cristiano Souza Oliveira - Instituto Federal de Educação Ciência e Tecnologia do Sertão Pernambucano Campus Petrolina - fabio.cristiano@ifsertao.edu.br https://orcid.org/0000-0002-2063-4014

Danielle Juliana Silva Martins - Instituto Federal de Educação Ciência e Tecnologia do Sertão Pernambucano Campus Petrolina - danielle.juliana@ifsertao.edu.br https://orcid.org/0000-0001-5293-6562

Josilene Almeida Brito - Instituto Federal de Educação Ciência e Tecnologia do Sertão Pernambucano Campus Petrolina - josilene.brito@ifsertao.edu.br https://orcid.org/0000-0002-4536-5981

Resumo: Nos dias atuais, tem se percebido a necessidade de introduzir conceitos relacionados à computação desde a educação básica, visto serem esses indispensáveis para a plena atuação nas profissões atuais e futuras. Desse modo, o Pensamento Computacional tem se mostrado uma alternativa na disponibilização desses conceitos. Diante disso, este trabalho objetiva relatar uma experiência na elaboração e aplicação de atividades de Pensamento Computacional para crianças do $2^{\circ}$ e $3^{\circ}$ ano do Ensino Fundamental, atendidas pelo projeto Academia HackTown do IF Sertão-PE. Para tanto, utilizou-se de estratégias diversificadas e lúdicas, como a Computação Desplugada, a Aprendizagem Baseada em Jogos e a Gamificação, com o intuito de despertar o interesse dos estudantes ao aprenderem conceitos técnicos de computação. Logo, a presente proposta se caracteriza por ser descritiva e de abordagem qualitativa, cujos resultados obtidos por meio de entrevista, sugerem que houve uma significativa evolução na aprendizagem dos alunos, e que esses se mostraram motivados e desafiados ao se depararem com os conteúdos computacionais propostos por meio das atividades.

Palavras-Chave: Pensamento Computacional. Ensino. Aprendizagem. Crianças.

\section{A playful approach to teaching Computational Thinking to children}

Abstract: Nowadays, the need to introduce concepts related to computing from Basic Education has been perceived, as these are essential for full performance in current and future professions. Thus, Computational Thinking has been shown to be an alternative in making these concepts available. Therefore, this work aims to report an experience in the development and application of Computational Thinking activities for children in the 2nd and 3rd year of Elementary School, attended by the Academia HackTown project at IF Sertão-PE. Therefore, diversified and playful strategies were used, such as Unplugged Computing, Game-Based Learning and Gamification, in order to awaken the interest of students when learning technical concepts of computing. Therefore, this proposal is characterized by being descriptive and with a qualitative approach, whose results obtained through interviews, suggest that there was a significant evolution in 
student learning, and that they were motivated and challenged when faced with the proposed computational content through the activities.

Keywords: Computational Thinking. Teaching. Learning. Kids.

\section{Introdução}

O Pensamento Computacional (PC) que, trata-se de saber utilizar os fundamentos da Ciência da Computação para identificar e resolver problemas de forma eficiente, tem se destacado como uma alternativa na disponibilização de conhecimentos relacionados à área de computação para diferentes públicos e contextos educacionais de forma dinâmica, bem como, no estímulo de diversas habilidades consideradas indispensáveis às profissões atuais e futuras.

Desse modo, Wing (2014) corrobora que o PC é uma habilidade fundamental para todas as pessoas e enfatiza que além da leitura e escrita deve-se acrescentá-lo às habilidades analíticas das crianças. E essa já é uma realidade em vários países. No Brasil, inclusive, tem-se reconhecido essa necessidade de introduzir conceitos computacionais desde as séries iniciais.

Entretanto, "pouco se tem avançado quanto à inserção do $\mathrm{PC}$ em nível educacional e governamental na educação básica brasileira" (PINHO, et. al 2016). E isso decorre de problemáticas como a falta de materiais didáticos pertinentes e desenvolvidos com base teórica apropriada (SHULZ e SCHMACHTENBERG, 2017), além de abordagens complexas empregadas no ensino, que, por vezes, se equiparam às utilizadas nos cursos de graduação.

Nesse sentido, Araújo et al. (2015) ponderam, que, diferentemente da abordagem utilizada no Ensino Superior, o ensino da computação na educação básica deve compreender técnicas para a resolução de problemas e o processo de raciocínio lógicomatemático. E, Pinho, et. al (2016) reiteram que a inserção da Computação na Educação Básica, pode se dar por meio do desenvolvimento de atividades que exploram o PC. Para tanto, o uso da abordagem lúdica, de acordo com alguns autores (GARLET, BIGOLIN e SILVEIRA, 2016; LEITE e SILVA, 2017), constitui uma forma de atrair a atenção para que os alunos consigam desenvolver mais facilmente as habilidades.

Considerando a relevância do que foi exposto, este trabalho relata uma experiência, em que se propôs o ensino de Pensamento Computacional para crianças do $2^{\circ}$ e $3^{\circ}$ ano do Ensino Fundamental, por meio de atividades lúdicas desenvolvidas e aplicadas no Projeto Academia HackTown ${ }^{1}$ - Escola Pública de Programação em Jogos e Robótica, do IF Sertão PE - Campus Petrolina, no ano de 2019.

\section{Fundamentação Teórica e Trabalhos relacionados}

O Pensamento Computacional (PC) é uma distinta capacidade criativa, crítica e estratégica humana de saber utilizar os fundamentos da Computação, nas mais diversas áreas do conhecimento, com a finalidade de identificar e resolver problemas, de maneira individual ou colaborativa, através de passos claros, de tal forma que uma pessoa ou uma máquina possam executá-los eficazmente (BRACKMANN, 2017).

1 É um projeto de Pesquisa e Extensão, que busca trabalhar de forma inovadora, envolvendo metodologias e ferramentas para o desenvolvimento do Pensamento Computacional por meio do ensino de programação em jogos e robótica para crianças e adolescentes. Disponível em: https://hacktown.ifsertao-pe.edu.br/. 
Dessa maneira, a Sociedade Brasileira de Computação (SBC, 2017), entende que é fundamental e estratégico para o Brasil que conteúdos de Computação sejam ministrados desde a Educação Infantil e por isso preconiza o PC como um dos três eixos do ensino de Computação para a educação básica, juntamente com Mundo Digital e a Cultura Digital.

A SBC (2017) considera ainda, que o ensino do PC não necessita de computadores e pode ser efetivado através de outros materiais que remetam este conhecimento. Nisso, menciona as atividades lúdicas como ponto de partida, perpassando por conceitos que podem ser trabalhados de forma concreta, permitindo ao aluno a familiarização e a experiência com conteúdos computacionais.

Nesse sentido, no Brasil diversas iniciativas de introdução ao Pensamento Computacional no Ensino Básico, apontam resultados promissores e dessa forma, contribuem para a sustentação desse trabalho. Uma delas é pontuada por Shulz e Schmachtenberg (2017), em que os autores relatam a aplicação de um material didático 'desplugado' para ensinar representação binária a alunos do $4^{\circ}$ ano do Ensino Fundamental oportunizando a esses, o contato com a Computação por meio de atividades.

Outra proposta que versa com o presente trabalho, é a de Gomes, Melo e Tedesco (2016), visto que descreve uma experiência no ensino de programação baseada em jogos digitais para crianças com idades entre 5 e 6 anos de uma escola da rede privada. Nessa proposta, os autores destacam o engajamento dos alunos e sugerem que os jogos digitais favoreceram a apresentação dos conteúdos para tal público.

Nesse contexto, o trabalho de Lopes, Santana e Braga (2020) também é relevante, pois relata a experiência em um curso de Pensamento Computacional para alunos do Ensino Fundamental, utilizando jogos desplugados e elementos de Gamificação para engajar os discentes no decorrer das aulas. Como resultado, os autores apontam que a ludicidade promovida por meio dos jogos e da Gamificação foi um fator importante para a satisfação dos alunos participantes.

Assim, os trabalhos correlatos supracitados, partilham da utilização de métodos e técnicas que têm se destacado por estimular e motivar no processo de ensino e aprendizagem de conceitos computacionais, a saber: a Computação Desplugada, a Aprendizagem Baseada em Jogos e a Gamificação.

A Computação Desplugada, trata-se de uma iniciativa de professores de universidades da Nova Zelândia e da Austrália, cujo intuito é propagar fundamentos de Ciência da Computação sem o uso de computadores, utilizando-se para esse fim de atividades lúdicas (BELL et.al 2011). Esta, pela efetividade e relevância tem se sobressaído como uma alternativa para escolas que não possuem condições de ensinar Computação utilizando o computador como ferramenta.

Diferente desta, a metodologia Aprendizagem Baseada em Jogos (GBL - Game Based Learning) tem foco na concepção, no desenvolvimento, no uso e aplicação de jogos na educação e na formação (CARVALHO, 2015). Em se tratando especificamente do uso de jogos para a aprendizagem, esses têm se mostrado eficazes, pois partindo de objetivos educativos promovem a resolução de situações problemáticas, a aplicação de conceitos em situações práticas e, podendo ser colaborativos, desenvolvem o respeito 
pelos outros, o trabalho em equipe e a aprendizagem colaborativa sempre num ambiente de motivação permanente, como salientado por Riyis (2013).

Por fim, a Gamificação, que enquanto método abrange a utilização de mecanismos de jogos - como mecânicas e dinâmicas - em ambientes que não são jogos, para a resolução de problemas, para a motivação e o engajamento de um determinado público, e tem sido aplicada a atividades em que é preciso estimular o comportamento do indivíduo (VIANNA et al., 2013).

Logo, tendo em vista as contribuições proporcionadas por tais métodos, o presente trabalho se utilizou desses, na elaboração, bem como, aplicação de atividades lúdicas envolvendo conceitos voltados à inserção do Pensamento Computacional para crianças com faixa etária de 7 e 8 anos de idade, como é apresentado a seguir.

\section{Materiais e Métodos}

No tocante aos objetivos, a presente proposta é descritiva, e relata a experiência na aplicação de um curso de programação em jogos e robótica realizado na modalidade Formação Inicial e Continuada (FIC), no âmbito do Projeto Academia HackTown Escola Pública de Programação em Jogos e Robótica, do IF Sertão Pernambucano Campus Petrolina - PE, em 2019. Esta, possui ainda cunho qualitativo cuja análise foi feita por meio de uma entrevista com perguntas sobre os conteúdos abordados no curso, e se utilizou de uma gravação de áudio e de folhas de respostas, como instrumentos de coleta dos dados.

O curso denominado KIDS 0, foi realizado com 12 (doze) alunos do $2^{\circ}$ e $3^{\circ}$ ano do Ensino Fundamental I, entre esses, 2 (duas) meninas e um aluno com síndrome de Asperger $^{2}$. Este teve duração de seis meses com carga horária total de 30 horas dispostas entre 4 (quatro) fases, a saber: a primeira chamada "Entrando no jogo" que propôs a Introdução ao Pensamento Computacional; a segunda denominada "O mundo de LEGO", que visou a Introdução à Robótica LEGO; a terceira, chamada "Mundo dos Blocos", que buscou o estímulo ao Pensamento Criativo através do jogo Minecraft e da programação em blocos; e a última fase denominada "Lego Star", cujo o objetivo era propor noções de direção e lógica de programação aplicada a robótica.

As aulas ocorriam uma vez por semana, toda segunda-feira, com carga horária de 1 h e 30 minutos cada. O Quadro 1 a seguir, relaciona as metodologias utilizadas e a intenção que se buscou ao abordá-las nas atividades propostas na primeira fase do curso, que será detalhada neste trabalho.

Quadro 1. Relação das Metodologias empregadas e a intenção de uso.

\begin{tabular}{|l|l|}
\hline \multicolumn{1}{|c|}{ Metodologia } & \multicolumn{1}{c|}{ Intenção de Uso } \\
\hline Computação Desplugada & $\begin{array}{l}\text { Realização de atividades lúdicas sem o uso do } \\
\text { computador. }\end{array}$ \\
\hline Aprendizagem baseada em Jogos & Motivação e assimilação de conteúdos. \\
\hline Gamificação & Incentivo e avaliação por meio de ranking. \\
\hline
\end{tabular}

Fonte: Autoria própria.

\footnotetext{
${ }^{2}$ Síndrome considerada um tipo leve de autismo. 
Vale ressaltar que se deu ênfase às metodologias supramencionadas com o intuito de tornar as atividades mais significativas e lúdicas para os alunos, por se tratarem de conceitos da área tecnológica, e que por vezes são tidos como maçantes devido a sua complexidade.

\subsection{Dinâmica do curso}

A fase 1, teve 5 (cinco) encontros e abordou a introdução de conceitos referentes a lógica de programação, em que se buscou estimular as habilidades do Pensamento Computacional, que de acordo com Brackmann(2017) são: a decomposição de problemas, o reconhecimento de padrões, a abstração e o algoritmo.

Dessa forma, Liukas (2015) pontua que a decomposição é um processo pelo qual os problemas são quebrados em partes menores. E que o reconhecimento de padrões trata-se da busca por similaridades e padrões com o intuito de resolver problemas complexos de forma mais eficiente. Para isso, procura-se por elementos que sejam iguais ou muito similares em cada problema. Quanto à abstração, pondera ainda, que é um processo de separação de detalhes que não são necessários para se concentrar em coisas que são importantes.

Neste contexto, Wing (2014) considera que o algoritmo, é o elemento que agrega todos os demais, e o define como um plano, uma estratégia ou um conjunto de instruções claras necessárias para a formulação e solução de um problema.

Desse modo, as aulas tinham a nomenclatura substituída por "Aventura”, bem como as atividades eram chamadas de "Missões", e cada uma dessas pontuou habilidades específicas do PC, conforme pode ser visto no Quadro 2. Nisso, buscou-se reproduzir os benefícios alcançados com o ato de jogar, como por exemplo, o aumento da motivação e atenção, assim como, o desenvolvimento cognitivo dos alunos (CAMPIGOTTO et al. 2013).

Quadro 2. Descrição das missões trabalhadas durante as aulas

\begin{tabular}{|c|c|c|c|c|}
\hline Aventura & Conteúdo & Missão de sala & Missão de casa & Habilidades do PC \\
\hline$\# 01$ & $\begin{array}{c}\text { Conceito de } \\
\text { Algoritmo }\end{array}$ & $\begin{array}{l}\text { Montar desenhos } \\
\text { de brinquedos } \\
\text { através de um } \\
\text { passo a } \\
\text { passo enumerado. }\end{array}$ & $\begin{array}{l}\text { Descrever o } \\
\text { passo a passo } \\
\text { da montagem } \\
\text { de um dos } \\
\text { brinquedos } \\
\text { montados em } \\
\text { sala. }\end{array}$ & $\begin{array}{c}\text { Algoritmo e } \\
\text { Decomposição de } \\
\text { problemas por meio da } \\
\text { identificação de passos } \\
\text { e decisões em um } \\
\text { algoritmo. }\end{array}$ \\
\hline \#02 & $\begin{array}{c}\text { Conceito de } \\
\text { Variável }\end{array}$ & $\begin{array}{l}\text { Organizar objetos } \\
\text { do dia a dia em } \\
\text { variáveis } \\
\text { apropriadas. }\end{array}$ & $\begin{array}{l}\text { Ligar objetos } \\
\text { as variáveis } \\
\text { relacionadas a } \\
\text { cada objeto. }\end{array}$ & $\begin{array}{l}\text { Abstração por meio da } \\
\text { comparação de } \\
\text { informações e } \\
\text { organização de dados. }\end{array}$ \\
\hline$\# 03$ & $\begin{array}{l}\text { Programa, } \\
\text { Instruções e } \\
\text { Lógica } \\
\text { Sequencial }\end{array}$ & $\begin{array}{l}\text { Seguir e criar } \\
\text { instruções } \\
\text { sequenciais num } \\
\text { contexto de Festa } \\
\text { de aniversário. }\end{array}$ & $\begin{array}{l}\text { Seguir e criar } \\
\text { instruções } \\
\text { sequenciais } \\
\text { semelhantes às } \\
\text { realizadas em } \\
\text { sala. }\end{array}$ & $\begin{array}{c}\text { Abstração e } \\
\text { Decomposição de } \\
\text { problemas através da } \\
\text { comparação de } \\
\text { informações e } \\
\text { identificação de passos } \\
\text { e decisões em um } \\
\text { algoritmo. }\end{array}$ \\
\hline
\end{tabular}




\begin{tabular}{|c|c|c|c|c|}
\hline \#04 & $\begin{array}{c}\text { Lógica } \\
\text { Condicional }\end{array}$ & $\begin{array}{c}\text { Realizar desafios } \\
\text { de programação } \\
\text { na plataforma } \\
\text { Compute.it }{ }^{3} \text {. }\end{array}$ & $\begin{array}{c}\text { Realizar } \\
\text { comandos } \\
\text { condicionais } \\
\text { num contexto } \\
\text { de um passeio } \\
\text { ao parque. }\end{array}$ & $\begin{array}{l}\text { Reconhecimento de } \\
\text { padrões identificando, } \\
\text { entendendo e } \\
\text { explicando em que } \\
\text { situações o computador } \\
\text { pode ou não ser } \\
\text { utilizado para } \\
\text { solucionar um } \\
\text { problema. }\end{array}$ \\
\hline \#05 & $\begin{array}{l}\text { Lógica de } \\
\text { Repetição }\end{array}$ & $\begin{array}{l}\text { Realizar desafios } \\
\text { Loops in } \\
\text { Collector }{ }^{4} \text { na } \\
\text { plataforma } \\
\text { Code.org. }\end{array}$ & $\begin{array}{l}\text { Contar e pintar } \\
\text { por meio de } \\
\text { repetições. }\end{array}$ & $\begin{array}{l}\text { Algoritmo através da } \\
\text { execução adequada de } \\
\text { algoritmos contendo } \\
\text { repetições por meio de } \\
\text { uma linguagem } \\
\text { simbólica e do } \\
\text { português. }\end{array}$ \\
\hline
\end{tabular}

Fonte: Autoria própria.

Para o entendimento dos conteúdos tratados em cada aventura, buscou-se simplificar a linguagem, adaptando-a, e utilizando-se de ilustrações, bem como, situações do dia a dia dos aprendizes. O conceito de variável ${ }^{5}$ apresentado na aventura \#02 (dois), por exemplo, foi abordado através da ilustração de um álbum de figurinhas, como mostrado na Figura 1 abaixo.

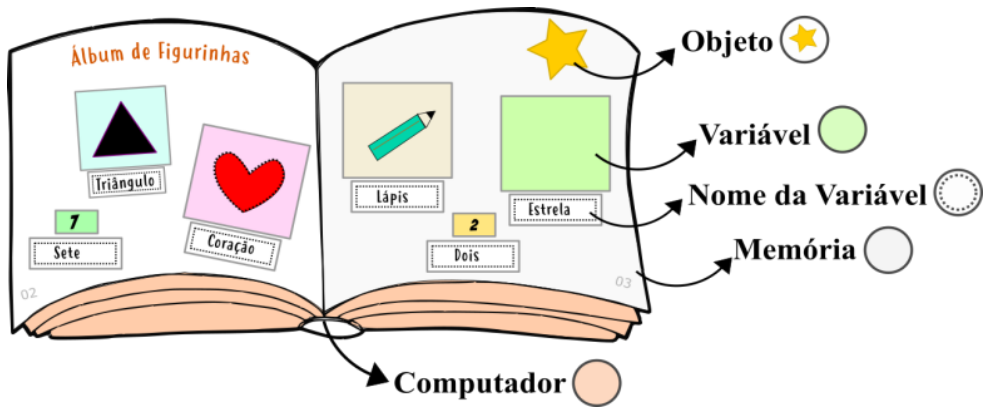

Figura 1. Ilustração - álbum de figurinhas

Fonte: Autoria própria.

Nessa ilustração, cada figura do álbum representa um objeto a ser guardado em seu próprio espaço que possui um nome ou identificação. O espaço de cada figura representa as variáveis. As páginas do álbum representam a memória. E o álbum de figurinhas, representa o computador.

Outro conteúdo que se utilizou dessa mesma abordagem significativa e simplificada foi o de Estrutura Condicional. Para isso, buscou-se propor a ideia de um semáforo na missão realizada, em que os alunos deveriam utilizar a lógica para fazer com que a personagem $\mathrm{Carol}^{6}$, ao sair para passear no parque, atravessasse a rua de maneira consciente, como apresenta a Figura 2.

\footnotetext{
3 Disponível em: <http://compute-it.toxicode.fr/>. Acesso em 14 de Abril de 2021.

4 Disponível em: $<$ https://studio.code.org/s/coursea-2020/stage/9/puzzle/1>. Acesso em 14 de Abril de 2021.

5 Espaço reservado na memória do computador para guardar informações que serão utilizadas durante o código do programa. Podem ter valores de diversos tamanhos e tipos, tais como números inteiros, números reais, caracteres e valores lógicos.

${ }^{6}$ Personagem contadora de histórias do projeto Academia HackTown.
}

V. $19 \mathrm{~N}^{\mathrm{o}} 1$, julho, 2021

RENOTE

DOI: https://doi.org/10.22456/1679-1916.118546 


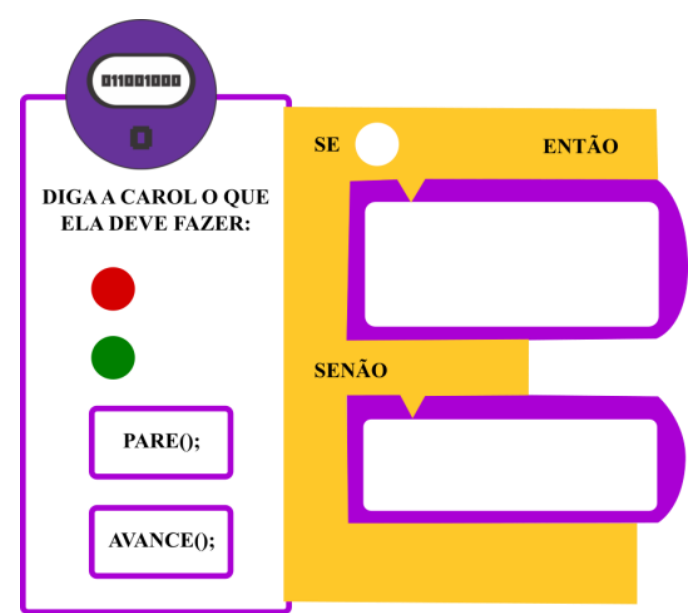

Figura 2. Missão utilizando a lógica condicional por meio de um semáforo Fonte: Autoria própria.

Nessa missão o programa pode ser interpretado de duas maneiras. A primeira assumindo a cor verde na condição "SE" executando assim o comando "Avance", e consequentemente na condição "SENÃO" o comando "Pare". Ou ainda, quando a cor vermelha estiver presente na condição "SE" executa-se o comando "Pare" e na condição "SENÃO" o comando avance.

Quanto à aplicação e correção desta, os alunos se mostraram exitosos em compreendê-la e concluí-la. Os mesmos chegaram ainda a sugerir que se poderia criar uma terceira condição, caso o sinal recebesse a cor amarela, a personagem deveria prestar atenção, demonstrando assim a fácil assimilação da lógica que esses tiveram.

Com relação à avaliação das atividades (missões), essa se deu por meio de um sistema gamificado, em que o aluno opta por utilizar um "nickname", que trata-se de um nome fictício pelo qual gostaria de ser conhecido pelos demais colegas de turma, e onde pode acompanhar seu progresso ao acessar o site da Academia HackTown ${ }^{7}$ na aba ranking. Nesse sistema cada atividade recebe um quantitativo de pontos, que ao final da fase soma um total de 1000 pontos e quanto maior a pontuação acumulada, mais acima no ranking o aluno fica.

Nesse sentido, ao final do curso KIDS 0 foi realizada uma entrevista, cujas perguntas foram exibidas uma a uma em um monitor de televisão - pertencente ao laboratório onde ocorriam as aulas do curso - e, desse modo, cada uma destas foi lida de maneira audível para que todos os alunos pudessem responder. Os resultados desta entrevista são apresentados na seção a seguir.

\section{Resultados e Discussão}

No total, foram aplicadas cerca de 10 (dez) atividades na fase 1, detalhada no presente trabalho, 5 (cinco) delas aplicadas durante as aulas em sala, e as demais foram impressas e enviadas para casa a fim de que os alunos pudessem revisar os conteúdos tratados.

Assim, a fim de perceber a relevância das atividades, estratégias e metodologias empregadas, foi realizada uma entrevista com perguntas previamente feitas relacionadas aos conteúdos ministrados durante as quatro fases do curso. E os dados foram colhidos

\footnotetext{
${ }^{7}$ Disponível em: <https://hacktown.ifsertao-pe.edu.br/public/ranking>. Acesso em 14 de Abril de 2021. 
no campo de ação, por meio de uma gravação de áudio e também de folhas de respostas, ambas autorizadas pelos pais e responsáveis dos alunos da turma KIDS 0 .

Vale ressaltar, que foi escolhida a entrevista ao invés de um questionário porque na turma em questão tinham 2 (dois) alunos com déficit de leitura e consequentemente complicações na escrita. Dessa maneira, os alunos com dificuldade de escrita, responderam às perguntas discursivas por meio de desenhos e de maneira audível para que ficasse registrado.

Nesse contexto, a entrevista foi realizada com 11 (onze) participantes. Para a fase 1, relatada neste trabalho, foram elaboradas 6 (seis) perguntas, sendo 5 (cinco) delas objetivas, de múltipla escolha, contendo quatro opções de respostas e 1(uma) discursiva. Logo abaixo, é mostrado na Figura 3, o percentual de acertos e erros relacionados às perguntas objetivas feitas para esta fase na entrevista.

Percentual de acertos e erros por pergunta objetiva

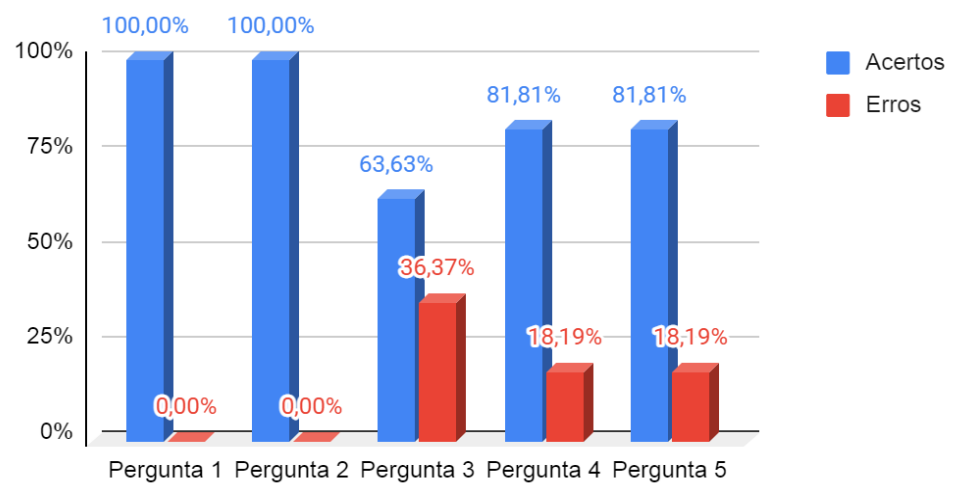

Figura 3. Gráfico representando o percentual de acertos e erros por perguntas objetivas.

Fonte: Autoria própria.

Ao propor os conceitos de Algoritmo e Variável, foram empregadas as metodologias Computação Desplugada e Gamificação. Nas perguntas 1 e 2, percebe-se que o emprego de tais metodologias podem ter auxiliado na fixação dos conteúdos, visto que, os conceitos de Algoritmo e Variável apresentados nas primeiras aula do curso, ainda foram lembrados pelos alunos participantes ao final do curso, uma vez que esses foram unânimes em responder as alternativas corretas.

Desse modo, percebeu-se também uma significativa evolução da aprendizagem dos alunos, que inicialmente no curso chegavam a confundir a palavra 'algoritmo' com 'algarismo', e conforme apresentado nas perguntas 1 e 2 da entrevista, esses se mostraram mais habituados com os conceitos aprendidos.

A pergunta 3, buscou relembrar as três formas principais que o computador utiliza para organizar suas instruções em um programa, a saber: lógica sequencial, condicional e de repetição. Quanto a esse questionamento, percebe-se que 63,63\% dos participantes conseguiram assimilar as estruturas de programação trabalhadas nas últimas aulas da fase 1. Durante a entrevista os alunos se mostraram confusos com a quantidade de palavras chave em cada alternativa dessa pergunta, o que pode ter contribuído para o resultado pouco expressivo em número de acertos.

Com relação à pergunta 4 , o conteúdo proposto foi estrutura condicional. Para tanto, foram utilizadas as metodologias Computação Desplugada, Aprendizagem V. $19 \mathrm{~N}^{\mathrm{o}} 1$, julho, 2021 
baseada em jogos e Gamificação na abordagem do conteúdo. Na aplicação da pergunta relacionada a esse conteúdo, foi mostrado um exemplo de programa simbólico que havia sido utilizado para a explanação desse conteúdo, na fase 1 do curso. Ao perceberem que se tratava do mesmo exemplo anteriormente visto nas aulas, os alunos se mostraram alegres e mencionaram que relembravam tal conteúdo, o que impactou nos resultados, visto que $81,81 \%$ dos entrevistados conseguiram relacionar a Lógica Condicional abordada na missão 4 (quatro) e proposta nessa pergunta.

Na pergunta 5, foi abordada a lógica sequencial, que se utilizou de ilustrações do dia a dia dos alunos para propor o conteúdo. Nesse sentido, foi perguntado "qual lógica faz com que o passo a passo (algoritmo) seja realizado um após o outro?", ao que 9 que corresponde ao percentual de $81,81 \%$ - dos alunos entrevistados responderam corretamente.

Em relação à lógica de repetição trabalhada na quinta aula da fase, essa ocorreu inicialmente por meio de uma dinâmica, e finalizou-se através de uma atividade na plataforma Code.org. Portanto, na pergunta discursiva da entrevista foi pedido que os alunos descrevessem uma situação em que precisassem repetir passos, ao que se obtiveram respostas como: "Escovar os dentes" - respondida por cinco(5) dos alunos "mastigar", "jogar vídeo game", "as dobraduras de papel que eu faço", "colocar o cadarço do sapato", "pentear o cabelo" e "andar".

Tais respostas apresentadas para essa pergunta demonstram a atenção dos alunos nas explicações dos conteúdos, que como já mencionado, buscaram se basear em situações do dia a dia, para dar maior significação à aprendizagem desses.

Com isso, através das respostas apresentadas na entrevista pôde-se notar que se obtiveram bons resultados com relação aos conceitos e conteúdos propostos por meio das atividades, e demonstraram ainda, que as metodologias empregadas se mostram eficazes para o ensino e aprendizado de conteúdos tecnológicos, pois estas apresentaram consideráveis contribuições na fixação e ainda explanação dos conteúdos propostos.

\section{Considerações Finais}

Ao longo desse trabalho, percebeu-se que a abordagem lúdica empregada vai de encontro com a proposta pela SBC (2017) para os anos iniciais do Ensino Fundamental, uma vez que esta promoveu as habilidades do PC por meio de situações do dia a dia dos aprendizes, permitindo assim, a familiarização e a experiência com os conteúdos tratados. Situações essas, que envolveram a identificação de passos e padrões, a percepção e aplicação de decisões em um algoritmo, a comparação e organização de informações, bem como, a utilização de uma linguagem simbólica para representar algoritmos.

Nesse sentido, acredita-se que as dinâmicas e metodologias utilizadas, contribuíram de maneira significativa para o engajamento dos alunos. O emprego da Gamificação como método avaliativo, por exemplo, cativava os alunos ao ponto deles ficarem empolgados em realizar as atividades e saber que ao final seriam pontuados por isso. Ademais, essas facilitaram a compreensão de conceitos relativamente difíceis da área tecnológica através da Computação Desplugada e das ilustrações empregadas.

Durante a fase a que se destina este trabalho, alguns alunos mencionaram que gostariam que as aulas ocorressem durante toda a semana, e não apenas na segunda- 
feira, demonstrando o interesse que esses tinham em aprender mais por meio das metodologias e atividades propostas no curso.

Com relação à aplicação dessas atividades, percebeu-se que os alunos se mostraram motivados ao realizá-las, e desafiados muitas vezes, pelo fato dessas abordarem conteúdos que eles ainda não têm acesso no ensino regular.

E pelo fato dos alunos se mostrarem motivados e engajados em todo processo, e ainda de não ter ocorrido evasão no curso proposto, acredita-se também que foi possível facilitar e proporcionar um novo significado a aprendizagem dos conteúdos relacionados à área de computação para estes.

Por fim, ressalta-se que esse trabalho culminou na riqueza de trocas de experiências com o público atendido, bem como, contribuiu em muitos aspectos para a formação da autora.

Deste modo, espera-se que propostas de atividades e metodologias como as utilizadas no presente relato, possam ultrapassar os muros dos cursos de Formação Inicial e Continuada e alcançar as escolas brasileiras de Ensino Básico, de modo a contribuir para a efetiva inserção do Pensamento Computacional para este público, desmistificando assim a ideia de que conceitos relacionados à computação estão restritos apenas a estudantes de nível superior.

\section{Referências}

ARAÚJO, D. C.; RODRIGUES, A. N.; SILVA, C. V. de A.; SOARES, L. S. (2015) “O Ensino da Computação na Educação Básica Apoiado por Problemas: Práticas de Licenciados em Computação". In: Anais do XXIII WEI (Workshop sobre Educação em Computação) Garanhuns.

BELL, T.; WHITTEN, I. H.; FELLOWS, M. "Computer Science Unplugged Ensinando Ciência da Computação sem o uso do computador". Disponível em: < https://bit.ly/3pNKNmp>. Acesso em 03 de Março de 2021.

BRACKMANN, C. P. Desenvolvimento do Pensamento Computacional através de atividades desplugadas na Educação Básica. Tese (Doutorado) - Universidade Federal do Rio Grande do Sul, Centro de Estudos Interdisciplinares em Novas Tecnologias na Educação, Programa de Pós Graduação em Informática na Educação, Porto Alegre, BRRS, 2017.

CAMPIGOTTO, R; MCEWEN, R; DEMANNS, C. (2013). "Especially social: Exploring the use of an iOS application in special needs classrooms". Journal Computers \& Education, Virginia, v. 60, p. 74-86.

CARVALHO, C. V. de. (2015). "Aprendizagem Baseada em Jogos (Game-Based Learning)". II World Congress on Systems Engineering and Information Technology. November 19 - 22, Vigo, SPAIN.

GARlET, D.; BIGOLIN, N. M.; SILVEIRA, S. R. (2016). "Uma Proposta para o Ensino de Programação de Computadores na Educação Básica”. Disponível em: < https://bit.ly/3oUQz4p >. Acesso em: 24 de Fevereiro de 2021. 
GOMES, T; MELO, J; TEDESCO, P. (2016). Jogos Digitais no Ensino de Conceitos de Programação para Crianças. In: Brazilian Symposium on Computers in Education (Simpósio Brasileiro de Informática na Educação-SBIE). p. 470.

LEITE, M. and da SILVA, S. F. (2017). "Redimensionamento da computação em processo de ensino na educação básica: $O$ pensamento computacional, o universo e a cultura digital”. In Workshop da Licenciatura em Computação , 804-813.

LIUKAS, L. (2015). Hello Ruby: adventures in coding. Feiwel \& Friends.

LOPES, A. F.; SANTANA, T. S.; BRAGA, A. H. (2020) O ensino de pensamento computacional por meio de jogos desplugados e olimpíadas científicas: um relato de experiência nos anos finais do Ensino Fundamental. In: Anais do XXVIII WEI Workshop sobre Educação em Computação. Cuiabá-MT.

PINHO, G.; WEISSHAHN, Y.; CAVALHEIRO, S.; REISER, R.; PIANA, C.; FOSS, L.; AGUIAR M.; DU BOIS, A. Pensamento Computacional no Ensino Fundamental: Relato de Atividade de Introdução a Algoritmos. V Congresso Brasileiro de Informática na Educação (CBIE 2016). Anais do XXII Workshop de Informática na Escola (WIE 2016).

RIYIS, M. T. (2013). "RPG e Educação". Disponível em: < https://bit.ly/3rr4jWh >. Acesso em: 03 de Março de 2021.

SBC - SOCIEDADE BRASILEIRA DE COMPUTAÇÃO (2017). Referenciais de Formação em Computação: Educação Básica. Disponível em: $<$ http://bit.ly/3bIgVCb>. Acesso em: 25 de Fevereiro de 2021.

SCHUlZ, J. M.; SCHMACHTENBERG, R. F. (2017). “Construindo o Pensamento Computacional: experiência com o desenvolvimento e aplicação de materiais didáticos desplugados". VI Seminário Nacional da Infância e Educação. UNISC.

VIANNA, Y.; VIANNA, M.; MEDINA, B; TANAKA, S. (2013). “Gamification, Inc.: como reinventar empresas a partir de jogos". MJV Press: Rio de Janeiro.

WING, J. M. (2014). Computational Thinking with Jeannette Wing. Columbia Journalism School. 